\title{
Physiological Role for Cholecystokinin in Reducing Postprandial Hyperglycemia in Humans
}

\author{
Rodger A. Liddle, Robert J. Rushakoff, Eugene T. Morita, Lorna Beccaria, Jacqueline D. Carter, and Ira D. Goldfine \\ Cell Biology Laboratory and Departments of Medicine and Nuclear Medicine, Mount Zion Hospital and Medical Center, San \\ Francisco, California 94120; and Departments of Medicine and Physiology, University of California, San Francisco, California 94143
}

\begin{abstract}
It is known that the ingestion of glucose alone causes a greater increase in plasma glucose levels than ingestion of the same amount of glucose given with other nutrients. Since physiological plasma concentrations of cholecystokinin (CCK) prolong gastric emptying, it is proposed that after a meal, CCK may modify plasma glucose levels by delaying glucose delivery to the duodenum. To evaluate the effect of CCK on oral glucose tolerance, plasma CCK, insulin, and glucose levels and gastric emptying rates were measured in eight normal males before and after the ingestion of $60 \mathrm{~g}$ glucose with the simultaneous infusion of either saline or one of two doses of CCK-8 (12 or 24 pmol/kg per h). Gastric emptying rates were measured by gamma camera scintigraphy of technetium $99 \mathrm{~m}$ sulfur colloid and plasma CCK levels were measured by a sensitive and specific bioassay.

Basal CCK levels averaged 1.0 $\pm 0.1 \mathrm{pM}$ (mean $\pm \mathrm{SEM}, n$ $=8$ ) and increased to $7.1 \pm 1.1 \mathrm{pM}$ after a mixed liquid meal. After glucose ingestion, but without CCK infusion, $C C K$ levels did not change from basal, and the gastric emptying $t_{1 / 2}$ was $68 \pm 3 \mathrm{~min}$. Plasma glucose levels increased from basal levels of $91 \pm 3.9 \mathrm{mg} / \mathrm{dl}$ to peak levels of $162 \pm 11 \mathrm{mg} / \mathrm{dl}$ and insulin levels increased from $10.7 \pm 1.8 \mu \mathrm{U} / \mathrm{ml}$ to peak levels of $58 \pm 11$ $\mu \mathrm{U} / \mathrm{ml}$. After glucose ingestion, with CCK infused at $24 \mathrm{pmol} /$ kg per h, plasma CCK levels increased to $8 \mathrm{pM}$ and the gastric emptying $t_{1 / 2}$ increased to $148 \pm 16 \mathrm{~min}$. In concert with this delay in gastric emptying, peak glucose levels rose to only $129 \pm 17 \mathrm{mg} \%$ and peak insulin levels rose to only $\mathbf{2 4 . 2} \pm 4.2$ $\mu \mathrm{U} / \mathrm{ml}$. With CCK at $12 \mathrm{pmol} / \mathrm{kg}$ per $\mathrm{h}$, similar but less dramatic changes were seen.

To demonstrate that endogenous CCK could modify the plasma glucose and insulin responses to oral glucose, oral glucose was given with $\mathbf{5 0} \mathrm{g}$ of lipid containing long-chain triglycerides. This lipid increased peak CCK levels to $3.7 \pm 0.9 \mathrm{pM}$. Concomitant with this rise in CCK was a delay in gastric emptying and a lowering of plasma glucose and insulin values.

To confirm that CCK reduced hyperglycemia by its effect on gastric motility, $36 \mathrm{~g}$ glucose was perfused directly into the duodenum through a nasal-duodenal feeding tube in four subjects. With duodenal perfusion of glucose, there was no change in plasma CCK levels, but plasma glucose levels increased
\end{abstract}

Address reprint requests to Dr. Rodger A. Liddle, Cell Biology Laboratory, Mount Zion Hospital and Medical Center, P. O. Box 7921, San Francisco, CA 94120.

Received for publication 17 April 1987 and in revised form 16 November 1987.

J. Clin. Invest.

(C) The American Society for Clinical Investigation, Inc. 0021-9738/88/06/1675/07 \$2.00

Volume 81, June 1988, 1675-1681 from basal levels of $93 \pm 5$ to $148 \pm 6 \mathrm{mg} / \mathrm{dl}$ and insulin levels rose from $10.6 \pm 3.5$ to $29.5 \pm 5.2 \mu \mathrm{U} / \mathrm{ml}$. When CCK was infused at $24 \mathrm{pmol} / \mathrm{kg}$ per $\mathrm{h}$, neither the plasma glucose nor insulin responses to the duodenal administration of glucose were modified. Thus we conclude that $\mathrm{CCK}$, in physiological concentrations, delays gastric emptying, slows the delivery of glucose to the duodenum, and reduces postprandial hyperglycemia. These data indicate, therefore, that $\mathrm{CCK}$ has a significant role in regulating glucose homeostasis in humans.

\section{Introduction}

Although food intake in normal humans is episodic rather than constant, plasma glucose levels remain regulated within a narrow range of $70-115 \mathrm{mg} / \mathrm{dl}$ (1). Two major factors that regulate plasma glucose levels are $(a)$ the rate of delivery of glucose and carbohydrates from the stomach to the duodenum, where they can be absorbed and $(b)$ the ability of absorbed glucose to release insulin. Both are regulated by the nature of the ingested nutrients, and by gut hormones and neurotransmitters.

Cholecystokinin (CCK) is an established gut hormone that is released after food ingestion and is known to regulate pancreatic exocrine secretion, gallbladder contraction, and bowel motility $(2,3)$. In addition to these actions on gastrointestinal functions, studies both in vivo and in vitro in several species have indicated that CCK stimulates insulin release (4-9). We Have recently developed a sensitive and specific bioassay for measuring plasma CCK levels in humans $(10,11)$. This assay allows detection of basal CCK levels, and is specific for CCK with no detectable interference from other hormones and neurotransmitters (11). Using this bioassay, we reported that the release of $\mathrm{CCK}$ is regulated primarily by the ingestion of protein, amino acids, and fat, and not by glucose (11). Moreover, we have recently shown that infusions of CCK, at physiological concentrations, potentiate amino acid-induced (but not glucose-induced) insulin secretion (12). Therefore, one mechanism whereby CCK prevents hyperglycemia after a meal is the augmentation of insulin release.

The intrinsic properties of ingested food, such as volume, osmolality, $\mathrm{pH}$, temperature, and ion and nutrient content affect the rate at which the stomach empties (13-17). In addition, earlier studies had suggested that CCK plays a role in regulating gastric emptying (18-21). To study the role of CCK on this function, we infused CCK at physiological concentrations into humans and found that CCK had a major part in delaying gastric emptying (21). Therefore, a second mechanism whereby CCK could prevent postprandial hyperglycemia would be in delaying the delivery of carbohydrate from the stomach to the duodenum.

It is well known that ingestion of glucose alone causes a greater rise in blood glucose levels than the same amount of 
glucose in a mixed meal also containing fat and protein (22, 23). Since glucose is not a major regulator of CCK secretion, it is possible that the postprandial hyperglycemia seen after the ingestion of carbohydrate alone is due, in part, to the lack of CCK release, which, if present, would have both augmented insulin secretion and delayed gastric emptying. In the present study, we have investigated the role of CCK-induced delayed gastric emptying on glucose tolerance. Normal human volunteers were given $60 \mathrm{~g}$ oral glucose in the presence and absence of CCK infusions. In these studies plasma CCK, glucose, and insulin levels and gastric emptying rates were measured. These experiments indicate that after the ingestion of glucose, CCK in physiological concentrations delays gastric emptying, slows the delivery of glucose to the duodenum, and reduces hyperglycemia.

\section{Methods}

Experimental subjects. Normal healthy male volunteers between 26 and $44 \mathrm{yr}$ of age were studied the morning after an overnight (12-15 h) fast. Volunteers were taking no medication before the study and all subjects were within $15 \%$ of ideal body weight. All experiments were performed between 8 and 11 a.m. The study was approved by the Committee on Protection of Human Subjects of Mount Zion Hospital and Medical Center and the Committee on Human Research of the University of California, San Francisco. Written informed consent was obtained from each subject.

Ingestion of liquid meal. As previously published (11, 12, 21), subjects were fed a standard mixed liquid meal consisting of instant breakfast supplement (Carnation Co., Los Angeles, CA), one egg, and half-and-half milk and cream, totaling $1.5 \mathrm{cal} / \mathrm{ml}$ and consisting of $40 \%$ carbohydrate (mostly in the form of sucrose), $40 \%$ fat, and $20 \%$ protein. This meal was given in a $400-\mathrm{ml}$ volume and consumed over a $1-2-m i n$ period. Blood was sampled before the meal and at various times up to $90 \mathrm{~min}$ after feeding.

Ingestion of glucose, intravenous infusions, and measurement of gastric emptying. Eight subjects were administered orally $400 \mathrm{ml}$ of a glucose solution containing $60 \mathrm{~g}$ of glucose to which $100 \mu \mathrm{Ci}$ of technetium $\left({ }^{99 \mathrm{~m}} \mathrm{Tc}\right){ }^{1}$ sulfur colloid had been added. On three separate days and in random order, the same subjects were studied under the following conditions: $(a)$ ingestion of glucose with the simultaneous intravenous infusion of saline, $(b)$ ingestion of glucose with simultaneous infusion of CCK-8 at a rate of $12 \mathrm{pmol} / \mathrm{kg}$ per $\mathrm{h}$, and $(c)$ ingestion of glucose with simultaneous infusion of CCK-8 at a rate of $24 \mathrm{pmol} / \mathrm{kg}$ per $\mathrm{h}$. Infusions were started $10 \mathrm{~min}$ before the ingestion of glucose and lasted for $100 \mathrm{~min}$. For these studies, synthetic CCK-8 (Kinevac, Squibb Diagnostics, New Brunswick, NJ) was diluted to appropriate concentrations in a total volume of $20 \mathrm{ml}$ saline. The actual infusion rates of CCK were determined by measuring the CCK concentration of the infusate taken from the delivery system (1i). This measurement corrects for losses of CCK by adsorption of syringes and intravenous tubing. All infusions were given into an antecubital vein using a Harvard pump (Harvard Apparatus Co., Inc., The Ealing Corp., S. Natick, MA). Blood samples were drawn from the contralateral arm. No adverse effects from the CCK infusion were reported by any subjects.

Determinations of gastric emptying were made by gamma scintigraphy of the abdomen (21). A gamma camera interfaced to a computer (ADAC 3350; Analytical Development Assoc. Corp., San Jose, CA) and fitted with a high resolution, low energy, parallel hole collimator was used for imaging. Subjects remained seated between counts but stood in front of the camera for counts taken every $5 \mathrm{~min}$ for the first $30 \mathrm{~min}$ of the test, and every $15 \mathrm{~min}$ thereafter. Although data were collected in both the anterior and posterior projections, only the anterior views were used in calculating the gastric emptying, since the

1. Abbreviations used in this paper: ${ }^{99 \mathrm{~m}} \mathrm{Tc}$, technetium $99 \mathrm{~m}$. geometric means of the anterior and posterior projections were very similar to those of the anterior views alone (24). Data were stored on computer disks for subsequent analysis. Using the computer display, the gastric regions were outlined, excluding the small intestine. For each time point, the total radioactivity in the region of interest was summated. Background counts were subtracted and corrections for radionuclide decay were calculated to yield final values for residual radioactivity remaining in the stomach. Background counts were small with respect to the total counts. Counts in the gastric region were expressed as a percentage of the total counts in the whole field in the first five postcibal minutes. The stomach and whole body radiation doses were calculated to be 11 and 1.7 mrads, respectively, for each study (calculations by Mr. Phillip Purser, Mt. Zion Hospital and Medical Center, San Francisco, CA).

Ingestion of glucose and fat. Four of the subjects studied above were also administered orally $400 \mathrm{ml}$ of a solution containing $60 \mathrm{~g}$ glucose and $50 \mathrm{~g}$ lipid (primarily long-chain triglycerides, Lipomul; Upjohn Co., Kalamazoo, MI) to which $100 \mu \mathrm{Ci}$ of ${ }^{99 \mathrm{~m}} \mathrm{Tc}$ sulfur colloid had been added. Blood was drawn at various times before and after drinking for measurements of plasma CCK, glucose, and insulin levels. Gastric emptying was measured as described above.

Blood sampling and hormone assays. Blood was drawn into iced, heparinized tubes and immediately centrifuged at 2,500 g. Plasma was divided and either immediately extracted for measurement of CCK $(10,11)$, stored at $-20^{\circ} \mathrm{C}$ for determination of insulin levels, or kept fresh on ice for prompt measurement of glucose levels. Plasma glucose concentrations were measured by the glucose oxidase method (Worthington Statzyme; Cooper Biomedical, Malvern, PA) (25). Plasma insulin concentrations were measured by RIA using a double antibody technique (26).

Plasma CCK concentrations were measured by a highly specific and sensitive bioassay as previously described $(10,11)$. This assay is based on the ability of CCK to stimulate amylase release from isolated rat pancreatic acini. Briefly, plasma was extracted and concentrated by adsorption onto octadecylsilylsilica (C-18 Sep-Pak; Waters Associates, Millipore Corp., Milford, MA) cartridges. CCK was then eluted with 1 $\mathrm{ml}$ of $80 \%$ ethanol and $0.2 \%$ trifluoroacetic acid and the extracts were dried under nitrogen. Plasma extracts were then incubated with isolated rat pancreatic acini for $30 \mathrm{~min}$ at $37^{\circ} \mathrm{C}$ and the amylase released into the incubation medium assayed, using procion yellow-coupled starch as substrate. Amylase release expressed as percent of total amylase content was compared with a dose-response curve for CCK-8. With this method, plasma CCK levels as low as $0.2 \mathrm{pM}$ could be detected. The recoveries of CCK-8 and CCK-33 added to charcoalstripped plasma were $90 \pm 5$ and $86 \pm 12 \%$, respectively (11). Intraassay and interassay coefficients of variation were 7.4 and $10.4 \%$, respectively.

The extensive studies and controls to validate this assay have been previously published $(10,11)$. In brief, several lines of evidence verified that the amylase stimulatory properties of plasma extracts on isolated pancreatic acini were indeed due to $\mathrm{CCK}$, as previously demonstrated $(10,11)$. First, CCK bioactivity in plasma was completely inhibited by either of two CCK antagonists, dibutyryl cyclic guanosine monophosphate (dibutyryl cGMP) or L-364,718 (Merck, Sharp \& Dohme Research Laboratories, West Point, PA). Second, all of the amylase stimulatory activity of plasma extracts could be removed by immunoadsorption of plasma with an antibody directed against the carboxy terminus of CCK. Third, maximum secretory concentrations of vasoactive intestinal peptide, a pancreatic secretagogue that increases intracellular cAMP levels, did not modify the calculated concentrations of CCK in plasma, indicating that vasoactive intestinal peptide and secretin, whose effects are mediated by intracellar cAMP, were not interfering with the estimated amount of CCK present in the extracts. Fourth, plasma bioactivity was not inhibited by atropine, indicating that muscarinic agents were not contributing to the amylase released by plasma extracts. And fifth, there was little interference from gastrin, as it was only 0.001 times as potent as CCK-8 in this system. 
Plasma CCK bioactivity was reproduced by infusing synthetic CCK-8. We have previously demonstrated that several forms of CCK circulate in plasma, ranging in size from CCK-33 to CCK-8 (11). Since CCK-8 and CCK-33 have very similar bioactivities on a variety of different target tissues (27) and we have recently confirmed this similarity in our bioassay system (28), CCK-8 can be infused to reproduce the total CCK bioactivity of plasma as we have previously demonstrated in studies of gallbladder contraction (11) and gastric emptying (21).

Duodenal perfusion of glucose. In additional studies, four subjects had nasal-duodenal feeding tubes placed for the direct instillation of glucose into the duodenum. For these studies a $10 \mathrm{Fr}$ Graphprobe enteral feeding tube (Zinetics Medical, Salt Lake City, UT) containing a pH electrode was introduced through the nose and localized beyond the pylorus by monitoring the intraluminal $\mathrm{pH}$. The gastric $\mathrm{pH}$ was consistently $<2.0$ and a prompt stepup to a $\mathrm{pH}$ of $>6.0$ was observed in all patients as the tip of the catheter passed into the duodenum. The tip of the feeding tube was maintained at $65 \mathrm{~cm}$ from the nares in all studies and the intraluminal $\mathrm{pH}$, confirmed throughout each study, was consistently $>6.0$. After baseline sampling of blood, subjects received intravenous infusions of either saline or CCK-8 at $24 \mathrm{pmol} / \mathrm{kg}$ per h. 10 min after initiating the infusion, glucose $(36 \mathrm{~g}$ in $240 \mathrm{ml})$ was perfused through the duodenal feeding tube at a rate of $160 \mathrm{ml} / \mathrm{h}$ for 90 min. Blood was drawn at various times for measurements of plasma CCK, glucose, and insulin levels.

Statistical analysis. All values are expressed as the mean \pm SEM. Differences in plasma glucose and hormone levels were compared using two-way analysis of variance with repeated measures and posthoc analysis was by the Newman-Keuls test (29). $P$ values of $<0.05$ were considered significant.

\section{Results}

Plasma CCK, glucose, and insulin responses to feeding a mixed liquid meal

The stimulatory effect of food on plasma CCK levels was studied in eight normal male volunteers (Fig. 1). Each subject was fed $400 \mathrm{ml}$ of a mixed liquid meal containing $60 \mathrm{~g}$ of carbohydrate plus protein and fat. Plasma CCK levels were measured for up to $90 \mathrm{~min}$. Fasting levels of CCK averaged $1.0 \pm 0.1 \mathrm{pM}$ CCK-8 equivalents and rose promptly to $7.1 \pm 1.1 \mathrm{pM}$ within $10 \mathrm{~min}$ of feeding. CCK levels declined over the next $20 \mathrm{~min}$ to $3.9 \mathrm{pM}$ and remained elevated for the $90-\mathrm{min}$ period of study. After the subjects consumed this carbohydrate-containing meal, they showed no significant increase in plasma glucose levels $(96-104 \mathrm{mg} / \mathrm{dl})$. In contrast, plasma insulin levels rose from $10.5 \pm 4.6 \mu \mathrm{U} / \mathrm{ml}$ to peak levels of $60.8 \pm 11.9 \mu \mathrm{U} / \mathrm{ml}$ within 45 min of feeding.

Plasma CCK, glucose, and insulin responses to feeding glucose in the absence and presence of CCK infusions

$C C K$ responses. Eight normal volunteers were fed $60 \mathrm{~g}$ of glucose in $400 \mathrm{ml}$ of water on three occasions. On one occasion no CCK was infused intravenously and on the other occasions CCK was infused at 24 and $12 \mathrm{pmol} / \mathrm{kg}$ per $\mathrm{h}$. Ingestion of $60 \mathrm{~g}$ glucose without CCK infusion did not significantly increase plasma CCK levels above basal levels (Fig. 2). Ingestion of glucose plus infusion of CCK at $24 \mathrm{pmol} / \mathrm{kg}$ per h resulted in plasma CCK levels averaging $7.7 \pm 1.0 \mathrm{pM}$, a value similar to peak CCK levels observed after the liquid meal. Ingestion of glucose plus infusion of CCK at the lower dose resulted in CCK levels of $4.0 \pm 0.8 \mathrm{pM}$, a value similar to that seen during the second half of the meal.
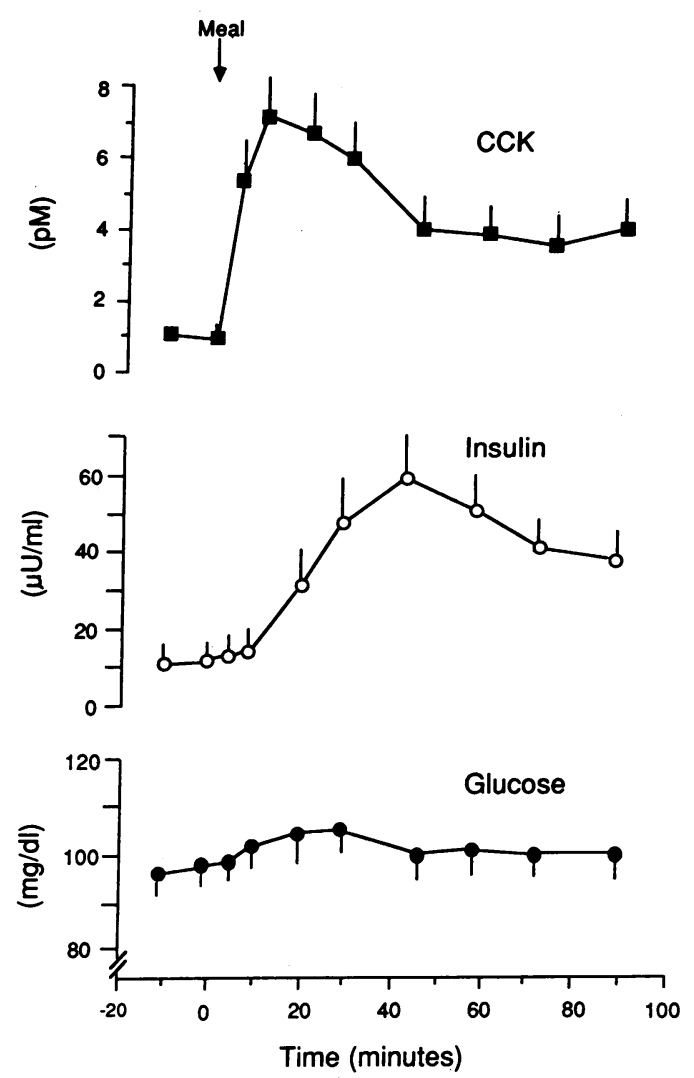

Figure 1. Plasma CCK, insulin, and glucose responses to feeding a mixed liquid meal. After a 12-15-h fast, eight male subjects were fed a 400-ml mixed liquid meal. Plasma was collected at the times indicated and CCK, insulin, and glucose levels were measured. Each value is the mean \pm SEM. All CCK values after the meal and insulin levels beyond $10 \mathrm{~min}$ of ingestion of the meal were statistically different from basal levels. No glucose values differed from basal levels.

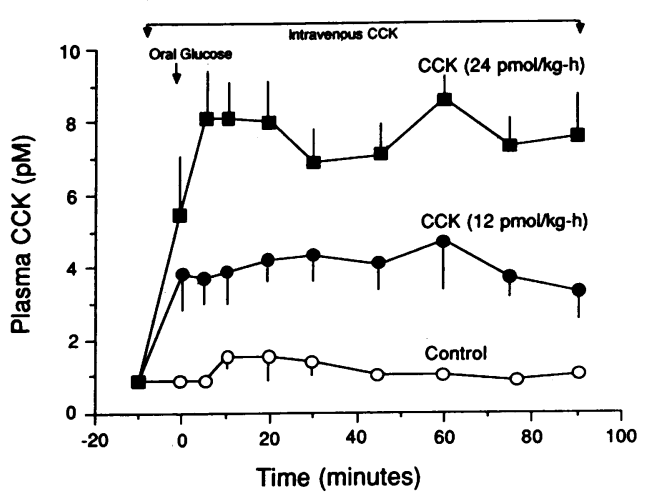

Figure 2. Plasma CCK levels with intravenous CCK administration. On three separate days, eight volunteers received 100-min infusions of either saline (o), CCK-8 at $12 \mathrm{pmol} / \mathrm{kg}$ per h (•), or CCK-8 at 24 $\mathrm{pmol} / \mathrm{kg}-\mathrm{h}(\boldsymbol{\omega})$. After beginning the infusions, subjects drank solutions containing $60 \mathrm{~g}$ glucose. At the times indicated, plasma was collected for measurement of CCK. Each value is the mean \pm SEM. All values during both low- and high-dose CCK infusions were statistically different from the levels during saline infusions. CCK levels during the high-dose CCK infusion were also significantly different from the low-dose CCK infusions. 


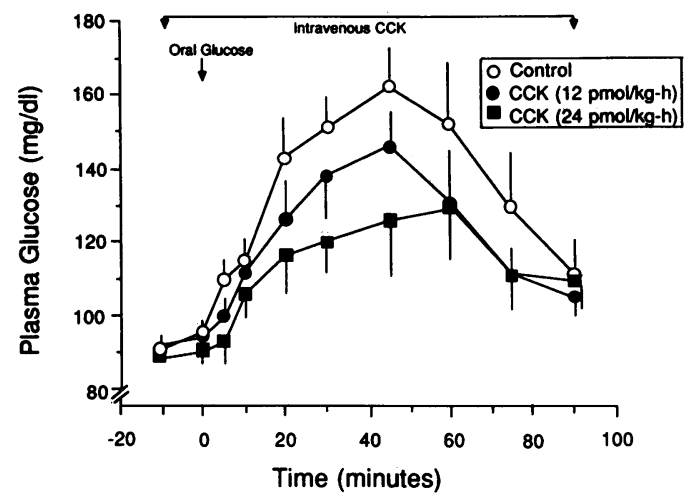

Figure 3. Effect of CCK on plasma glucose levels after the oral administration of glucose. Coincident with the saline (o) or CCK infusions of $12(\bullet)$ or $24(\square) \mathrm{pmol} / \mathrm{kg}$ per h shown in Fig. 2, all subjects drank $400-\mathrm{ml}$ solutions containing $60 \mathrm{~g}$ glucose at time 0 . At the times indicated, plasma was collected for measurement of glucose levels. Each value is the mean \pm SEM of the eight subjects.

Glucose responses. The ingestion of $60 \mathrm{~g}$ of glucose, in the absence of CCK infusion, increased plasma glucose levels from a basal value of $91 \pm 3.9 \mathrm{mg} / \mathrm{dl}$ to a peak value of $162 \pm 11 \mathrm{mg} / \mathrm{dl}$ (Fig. 3). Ingestion of glucose, in the presence of the high dose CCK infusion, resulted in significantly lower peak plasma glucose levels of $129 \pm 17 \mathrm{mg} / \mathrm{dl}$. Moreover, the integrated glucose response over the 90 -min sampling period was significantly lowered (Table I). Ingestion of glucose in the presence of the lower dose CCK infusion also resulted in decreased peak plasma glucose levels and a decreased integrated glucose response.

Insulin responses. Ingestion of glucose, without exogenous $\mathrm{CCK}$, increased plasma insulin levels from basal values of $10.7 \pm 1.8 \mu \mathrm{U} / \mathrm{ml}$ to peak levels of $58 \pm 11 \mu \mathrm{U} / \mathrm{ml}$ (Fig. 4 ). Ingestion of glucose with infusion of CCK at $24 \mathrm{pmol} / \mathrm{kg} \mathrm{per} \mathrm{h}$, however, resulted in lower peak levels of insulin at $24.2 \pm 4.2$ $\mu \mathrm{U} / \mathrm{ml}$. The integrated insulin response over $90 \mathrm{~min}$ in the presence of high dose CCK was less than one-third of the control value (Table I). Plasma insulin levels after glucose in-

Table I. Effect of CCK Infusion on Gastric Emptying Rates and Integrated Plasma Glucose and Insulin Responses to Oral Glucose

\begin{tabular}{cccc}
\hline Gastric emptying & $\Delta$ Glucose & $\Delta$ Insulin \\
\hline$t_{1 / 2}(\mathrm{~min})$ & $\mathrm{mg} / \mathrm{dl} \mathrm{per} 90 \mathrm{~min}$ & $\mu U / \mathrm{ml} \mathrm{per} 90 \mathrm{~min}$
\end{tabular}

CCK infusion rate

$\begin{array}{cccc}(\text { pmol/kg per } h) & & & \\ 0 & 68 \pm 3 & 1,045 \pm 177 & 3,400 \pm 396 \\ 12 & 104 \pm 10^{*} & 722 \pm 105^{*} & 1,859 \pm 275^{*} \\ 24 & 148 \pm 16^{*} & 649 \pm 190^{*} & 1,035 \pm 283^{*}\end{array}$

The areas under the curve for total glucose and insulin secretion in response to administration of $60 \mathrm{~g}$ glucose orally, together with either salinê, CÇ at $12 \mathrm{pmol} / \mathrm{kg}$ per h, or CCK at $24 \mathrm{pmol} / \mathrm{kg}$ per h are expressed as $\mathrm{mg} / \mathrm{dl} \mathrm{per} 90 \mathrm{~min}$ and $\mu \mathrm{U} / \mathrm{ml}$ per $90 \mathrm{~min}$, respectively. The integrated response is calculated from the area under the curve of the glucose or insulin response minus baseline. The $t_{1 / 2}$ for gastric emptying under the same conditions are expressed in minutes. $\left({ }^{*} P\right.$ $<0.05$ vs. saline).

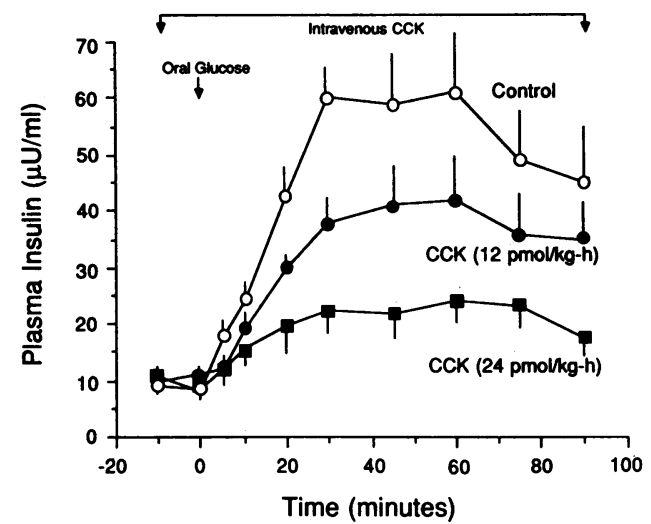

Figure 4. Effect of CCK on plasma insulin levels after the oral administration of glucose. Plasma insulin levels were measured before and after eight subjects drank $400-\mathrm{ml}$ solutions containing $60 \mathrm{~g}$ glucose at time 0 as shown in Figs. 2 and 3. Subjects received continuous infusions of either saline (o) or CCK at $12(\bullet)$ or $24(\square) \mathrm{pmol} / \mathrm{kg}$ per $h$. Each value is the mean \pm SEM of the eight subjects.

gestion with the lower dose CCK infusion also produced significantly lower peak and integrated insulin responses when compared with control values.

\section{Effect of CCK infusions on gastric emptying of oral glucose}

Since infusions of CCK lowered plasma glucose but did not increase insulin secretion after the ingestion of glucose, gastric emptying rates were measured to determine if CCK was delaying the delivery of glucose to the duodenum (Fig. 5). Without CCK, glucose emptied rapidly from the stomach. By 90 min, only $40 \pm 4.5 \%$ of the original gastric contents remained in the stomach. Infusion of CCK-8 at a rate of $12 \mathrm{pmol} / \mathrm{kg}$ per $\mathrm{h}$ resulted in a delay in gastric emptying such that $56 \pm 3.5 \%$ of the original volume remained in the stomach at $90 \mathrm{~min}$. This effect was dose dependent, as infusion of CCK-8 at $24 \mathrm{pmol} / \mathrm{kg}$ per $\mathrm{h}$ caused a more profound delay in emptying, such that $67.7 \pm 3.1 \%$ of the labeled solution was retained in the stomach.

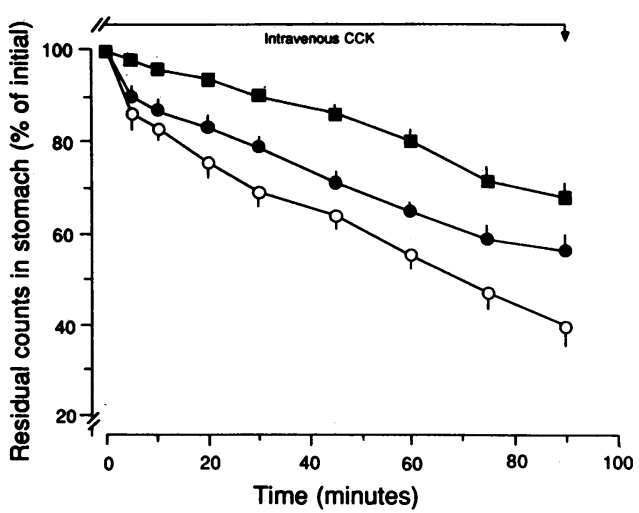

Figure 5. Effect of CCK on the gastric emptying rates of glucose. 10 min after beginning the respective infusions shown in Fig. 2 (saline (0) or CCK at $12(\bullet)$ or $24(\square)$ pmol/kg per h), each subject drank $400 \mathrm{ml}$ of a glucose solution labeled with $100 \mu \mathrm{Ci}$ of ${ }^{99 \mathrm{~m}} \mathrm{Tc}$-sulfur colloid. The amount of radioactivity remaining in the stomach was determined by scintigraphic scanning of the stomach in each subject. Values are expressed as the percent of total radioactivity in the stomach at the initial time 0 . Each value is the mean $\pm S E M$ of eight subjects. 
Effect of oral lipid and glucose on plasma CCK, glucose, and insulin levels, and gastric emptying

To determine if endogenously released CCK exhibited effects similar to those produced by CCK infusion, $50 \mathrm{~g}$ lipid was added to the oral glucose solution (Fig. 6). Ingestion of glucose alone did not affect plasma CCK levels, whereas ingestion of glucose plus lipid increased plasma CCK from basal levels of $0.9 \pm 0.1 \mathrm{pM}$ to $3.7 \pm 0.9 \mathrm{pM}$ within $10 \mathrm{~min}$ of feeding. CCK levels remained elevated for up to $90 \mathrm{~min}$. Coincident with this increase in CCK, the rate of gastric emptying of glucose and lipid was significantly slower than that of glucose alone. At the end of $90 \mathrm{~min}, 58.5 \pm 4.2 \%$ of the glucose plus lipid solution remained in the stomach, whereas after $90 \mathrm{~min}$, only $37.5 \pm 7.1 \%$ of the glucose-alone solution remained in the stomach $(P<0.05)$. Concomitant with this lipid-induced delay in gastric emptying, plasma glucose and insulin levels were also lower than those after glucose alone. After ingestion of glucose plus lipid, peak plasma glucose levels were $144 \pm 6.8$ $\mathrm{mg} / \mathrm{dl}$, whereas with glucose alone, levels were $167 \pm 9 \mathrm{mg} / \mathrm{dl}(P$ $<0.05$ ). Similarly, peak plasma insulin levels after glucose plus lipid ingestion were $46 \pm 6.2 \mu \mathrm{U} / \mathrm{ml}$, whereas with glucose alone, peak insulin levels were $62.7 \pm 7 \mu \mathrm{U} / \mathrm{ml}(P<0.05)$.

\section{Lack of an effect of CCK infusion on duodenally administered glucose}

To determine if CCK lowers postprandial hyperglycemia by delaying gastric emptying, plasma CCK, glucose, and insulin levels were measured in four subjects in whom glucose was perfused directly into the duodenum in the absence or presence of a CCK infusion (Fig. 7). $36 \mathrm{~g}$ of glucose was perfused
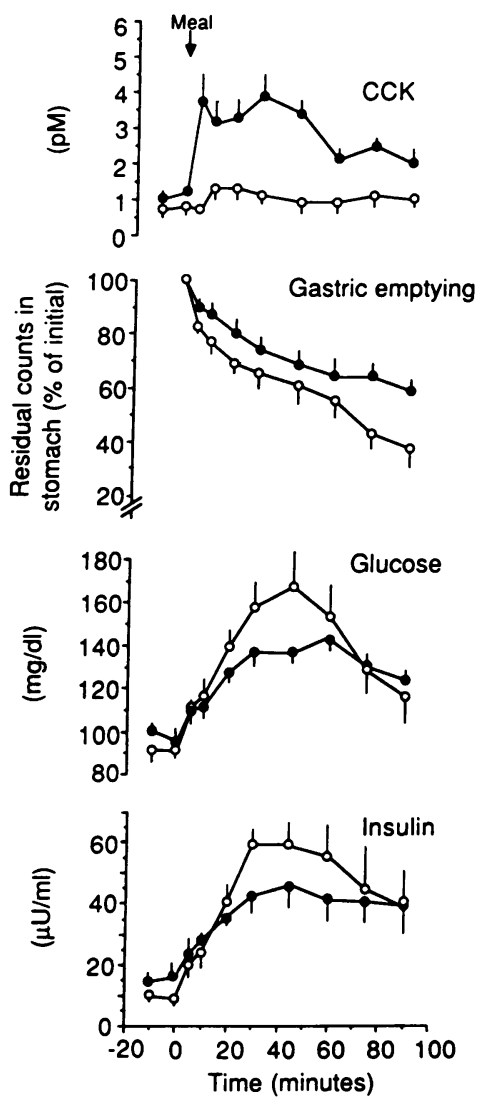

Figure 6. Effect of ora lipid and glucose on plasma CCK, glucose, and insulin levels, and gastric emptying. Four subjects were given $50 \mathrm{~g}$ Lipomul added to the solution of $60 \mathrm{~g}$ glucose in a total volume of 400 $\mathrm{ml}$ to which $100 \mu \mathrm{Ci}$ of ${ }^{99 \mathrm{~m}} \mathrm{Tc}$ sulfur colloid was added. Blood was drawn at the times indicated for measurements of plasma CCK, glucose, and insulin levels, and gastric emptying. The amount of radioactivity remaining in the stomach is expressed as the percent of total radioactivity in the stomach at time 0 . Symbols represent ingestion of either glucose (0) or glucose plus lipid (๑). Each value is the mean \pm SEM of four subjects.
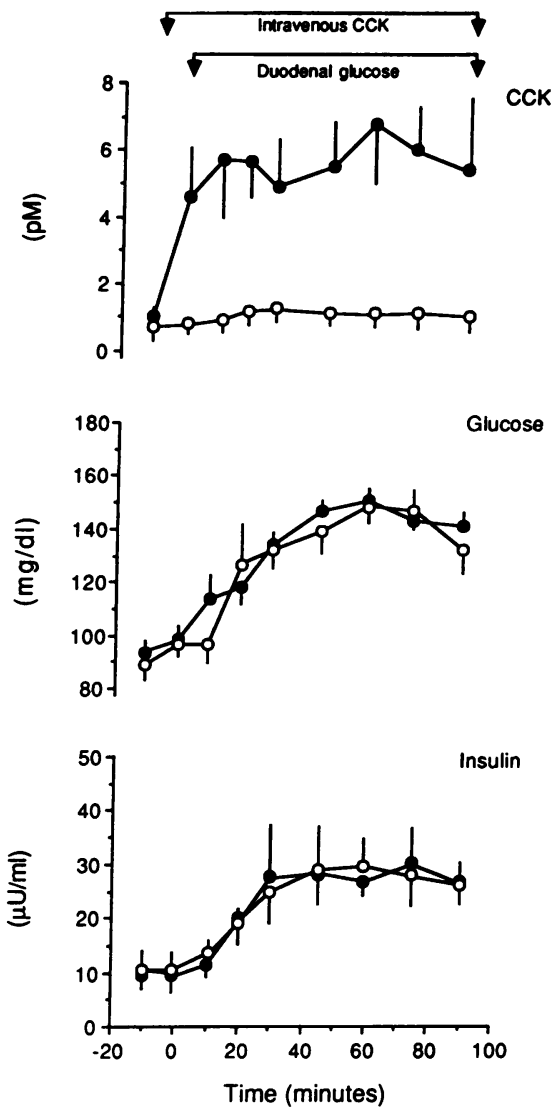

Figure 7. Lack of an effect of CCK infusion on duodenally administered glucose. Four subjects had feeding tubes placed into the duodenum through which $36 \mathrm{~g}$ glucose was perfused over $90 \mathrm{~min}$. After blood was collected at the -10 -min point, either saline (0) or CCK-8 at $24 \mathrm{pmol} / \mathrm{kg}$ per $\mathrm{h}(\bullet)$ was infused. Perfusion of glucose started at time 0 . Each value is the mean $\pm S E M$. over $90 \mathrm{~min}$. Basal CCK levels averaged $1.0 \pm 0.1 \mathrm{pM}$ and did not change with duodenal administration of glucose. On a subsequent day, CCK-8 was infused intravenously at 24 $\mathrm{pmol} / \mathrm{kg}$ per $\mathrm{h}$, producing steady state plasma levels of $5.6 \pm 1.3$ pM. With a control intravenous saline infusion together with the duodenal glucose administration, plasma glucose levels increased from $93 \pm 5 \mathrm{mg} / \mathrm{dl}$ to peak levels of $148 \pm 6 \mathrm{mg} / \mathrm{dl}$. With an intravenous infusion of CCK, there was no change in plasma glucose levels resulting from duodenal glucose administration. With the control infusion, plasma insulin levels increased from $10.6 \pm 3.5 \mu \mathrm{U} / \mathrm{ml}$ to $29.5 \pm 5.2 \mu \mathrm{U} / \mathrm{ml}$. With an infusion of CCK, there was no change in insulin levels resulting from the duodenal glucose perfusion.

\section{Discussion}

CCK was originally discovered because of its ability to stimulate gallbladder contraction (30). Subsequently, additional important actions of CCK on other areas of the gastrointestinal tract were elucidated, including stimulation of pancreatic enzyme secretion $(2,3,31)$, delaying of gastric emptying (18-21), and enhancement of small bowel motility $(2,3,32)$. These studies indicated, therefore, that the CCK released after a meal coordinates the delivery of food from the stomach to the duo- 
denum with concomitant biliary and pancreatic secretion, and increased transit through the small intestine.

Although CCK was first identified as a 33-amino acid polypeptide extracted from the intestine, other molecular forms of CCK originating from a common precursor have been identified in intestine, brain, and plasma. These forms include larger molecules such as CCK-58 and CCK-39 and smaller forms such as CCK-22, CCK-12, and CCK-4 (33-36). In human plasma, we have previously identified several CCK molecules. These include CCK-33, CCK-8, and a form intermediate in size between CCK-33 and CCK-8 (11). Recently, we compared the relative biological activities of CCK-8 and CCK-33 and found the two hormones to be nearly identical in potency (28), a finding also reported by Solomon et al. in a variety of target tissues in several species (27). Since pure synthetic CCK-8 (but not CCK-33) is readily available in large quantities, in the present and previous studies $(11,12,21)$ we have infused CCK-8 to reproduce the plasma CCK levels observed after a meal.

It has long been appreciated that hormones and gut factors participate in insulin and glucose metabolism. This appreciation comes from the observations that $(a)$ oral glucose is a more potent stimulant of insulin secretion (despite causing less hyperglycemia) than the same amount of glucose administered intravenously (37) and that $(b)$ duodenal extracts stimulate insulin secretion when injected into dogs and other animals (38). Several gut hormones have been studied for their ability to stimulate insulin secretion and have been termed incretins. The most extensively studied potential incretin has been glucose-dependent insulinotropic peptide, which stimulates insulin secretion in the presence of hyperglycemia (39). In rats and other species, CCK, like glucose-dependent insulinotropic peptide potentiates glucose-stimulated insulin secretion (4-9). In humans, however, we have recently observed that pure synthetic CCK, in physiological concentrations, potentiates amino acid-induced insulin secretion, but does not potentiate glucose-induced insulin secretion (12).

Although CCK does not potentiate glucose-stimulated insulin release, nevertheless, it may have an important role in regulating glucose metabolism through two interrelated mechanisms. First, it has been well documented that after eating a mixed meal there is a marked rise in insulin levels with little or no change in blood glucose levels (1). Our present studies with a mixed liquid meal gave very similar results. It is known that after the ingestion of a protein-containing meal, plasma amino acids increase (5). Since amino acids are potent stimuli of beta cell insulin release, a major stimulus for insulin release after a mixed meal is the increase in plasma amino acids. Since proteins and amino acids stimulate CCK release (11) and CCK potentiates amino acid-induced insulin secretion (12), it is likely, therefore, that the CCK released after the ingestion of a mixed meal plays an important role in regulating insulin secretion.

Second, the present study suggests an additional mechanism whereby CCK improves postprandial hyperglycemia. Previously we observed that after the ingestion of $400 \mathrm{ml}$ of water, the water emptied from the stomach with a $t_{1 / 2}$ of $<20$ min, whereas the same volume of a mixed liquid meal emptied with a $t_{1 / 2}$ of $>2 \mathrm{~h}(21)$. When water was ingested with concomitant infusions of CCK (to achieve plasma concentrations within the physiological range) the gastric emptying of water was similar to that of the mixed liquid meal. The data thus indicated that CCK was a major regulator of gastric emptying. In the present study, the gastric emptying of $400 \mathrm{ml}$ of glucose had a $t_{1 / 2}$ of $68 \mathrm{~min}$, a value intermediate between that of water and a mixed liquid meal. The infusion of CCK, at concentrations within the physiological range, delayed the emptying of glucose from the stomach and slowed the delivery of glucose to the duodenum. As a consequence of this CCK effect, glucose absorption from the intestine was delayed, resulting in smaller increases in plasma glucose levels. Moreover, this diminution of postprandial plasma glucose levels occurred despite decreased insulin release.

Two other independent lines of evidence indicated that the ability of CCK to reduce postprandial hyperglycemia involved an effect on gastric emptying. First, by bypassing the stomach and administering glucose directly into the duodenum, intravenous CCK had no effect on either plasma glucose or insulin levels. Second, adding lipid to the orally ingested glucose as a means of stimulating endogenous CCK secretion delayed gastric emptying and resulted in glucose and insulin levels lower than those seen with oral glucose alone. Together, these data suggest that the rate of gastric emptying is an important determinant of postprandial hyperglycemia and that CCK is an important regulator of gastric emptying.

The findings that CCK reduces postprandial hyperglycemia by both delaying gastric emptying and potentiating amino acid-induced insulin release extends the physiologic role of the integrative actions of this hormone. After a meal, in a highly coordinated fashion, CCK $(a)$ regulates the movement of nutrients through the gastrointestinal tract, $(b)$ contracts the gallbladder and stimulates pancreatic exocrine secretion to facilitate digestion, and $(c)$ to maintain euglycemia, potentiates amino acid-induced insulin secretion and delays gastric emptying. CCK thus has an essential role in regulating the intake, processing, and distribution of essential nutrients.

\section{Acknowledgments}

The authors thank Marilyn Morrissey and Dolores Olson for expert technical assistance in the performance of this study. The authors also wish to thank Dr. John A. Williams for helpful advice during the course of this work and preparation of the manuscript.

This work was supported by U. S. Public Health Service grants DK-01291 and DK-38626; grants from the American Diabetes Association and the Diabetes Treatment Centers of America Foundation; and grants from the Academic Senate and Research Evaluation and Allocation Committee of the University of California, San Francisco.

\section{References}

1. Tasaka, Y., M. Sekine, M. Wakatsuki, H. Ohgawara, and K. Shizume. 1975. Levels of pancreatic glucagon, insulin and glucose during twenty-four hours of the day in normal subjects. Horm. Metab. Res. 7:205-206.

2. Mutt, V. 1980. Cholecystokinin: isolation, structure and functions. In Gastrointestinal Hormones. G. B. Glass, editor. Raven Press, New York. 169-221.

3. Williams, J. A. 1982. Cholecystokinin: a hormone and a neurotransmitter. Biomed. Res. 3:107-21.

4. Unger, R. H., H. Ketterer, J. Dupre, and A. M. Eisentraut. 1967. The effects of secretin, pancreozymin, and gastrin on insulin and glucagon secretion in anesthetized dogs. J. Clin. Invest. 46:630-645.

5. Dupre, J., J. D. Curtis, R. H. Unger, R. W. Waddell, and J. C. 
Beck. 1969. Effects of secretin, pancreozymin, or gastrin on the response of the endocrine pancreas to administration of glucose or arginine in man. J. Clin. Invest. 48:747-757.

6. Otsuki, M., C. Sakamoto, H. Yuu, M. Maeda, S. Morita, A. Ohki, N. Kobayashi, K. Terashi, K. Okano, and S. Baba. 1979. Discrepancies between the doses of cholecystokinin or caerulein-stimulating exocrine and endocrine responses in perfused isolated rat pancreas. J. Clin. Invest. 63:478-484.

7. Szecowka, J., P. E. Lins, and S. Effendic. 1982. Effects of cholecystokinin, gastric inhibitory polypeptide, and secretin on insulin and glucagon secretion in rats. Endocrinology. 110:1268-1272.

8. Hermansen, K. 1984. Effects of cholecystokinin (CCK)-4, nonsulfated CCK-8, and sulfated CCK-8 on pancreatic somatostatin, insulin, and glucagon secretion in the dog: studies in vitro. Endocrinology. 114:1770-1775.

9. Verspohl, E. J., H. P. T. Ammon, J. A. Williams, and I. D. Goldfine. 1986. Evidence that cholecystokinin interacts with specific receptors and regulates insulin release in isolated rat islets of Langerhans. Diabetes. 35:38-43.

10. Liddle, R. A., I. D. Goldfine, and J. A. Williams. 1984. Bioassay of plasma cholecystokinin in rats: effects of food, trypsin inhibitor, and alcohol. Gastroenterology. 87:542-549.

11. Liddle, R. A., I. D. Goldfine, M. S. Rosen, R. A. Taplitz, and J. A. Williams. 1985. Cholecystokinin bioactivity in human plasma: molecular forms, responses to feeding, and relationship to gallbladder contraction. J. Clin. Invest. 75:1144-1152.

12. Rushakoff, R. J., I. D. Goldfine, J. D. Carter, and R. A. Liddle. 1987. Physiological concentrations of cholecystokinin stimulate amino acid-induced insulin release in humans. J. Clin. Endocrinol. \& Metab. 65:395-401.

13. Hunt, J. N., and D. F. Stubbs. 1975. The volume and energy content of meals as determinants of gastric emptying. J. Physiol. (Lond.). 245:209-225.

14. Barker, G. R., G. M. Cochran, G. A. Corbett, J. F. Dufton, J. N. Hunt, and S. K. Roberts. 1978. Glucose, glycine, and diglycine, in test meals as stimuli to a duodenal osmoreceptor slowing gastric emptying. J. Physiol. (Lond.). 283:341-346.

15. Bateman, D. N. 1982. Effects of meal temperature and volume on the emptying of liquid from the human stomach. J. Physiol. (Lond.). 331:461-467.

16. Hunt, J. N. 1983. Does calcium mediate slowing of gastric emptying by fat in humans? Am. J. Physiol. 244:G89-G94.

17. Hunt, J. N. 1984. Regulation of gastric emptying by neurohumoral factors and by gastric and duodenal receptors. In Esophageal and Gastric Emptying. A. Dubois and D. O. Castell, editors. CRC Press, Boca Raton, FL. 65-71.

18. Yamagishi, T., and H. T. Debas. 1978. Cholecystokinin inhibits gastric emptying by acting on both proximal stomach and pylorus. Am. J. Physiol. 234:E375-E378.

19. Moran, T. H., and P. R. McHugh. 1982. Cholecystokinin suppresses food intake by inhibiting gastric emptying. Am. J. Physiol. 242:R491-R497.

20. Anika, M. S. 1982. Effects of cholecystokinin and caerulein on gastric emptying. Eur. J. Pharmacol. 85:195-199.
21. Liddle, R. A., E. T. Morita, C. K. Conrad, and J. A. Williams. 1986. Regulation of gastric emptying in humans by cholecystokinin. $J$. Clin. Invest. 77:992-996.

22. Rabinowitz, D., T. J. Merimee, R. Maffezzoli, and J. A. Burgess. 1966. Patterns of hormonal release after glucose, protein, and glucose plus protein. Lancet. 454-457.

23. Bantle, J. P., D. C. Laine, G. W. Castle, J. W. Thomas, B. J. Hoogwerf, and F. C. Goetz. 1983. Postprandial glucose and insulin responses to meals containing different carbohydrates in normal and diabetic subjects. N. Engl. J. Med. 309:7-12.

24. Christian, P. E., F. L. Datz, J. A. Sorenson, and A. Taylor. 1983. Technical factors in gastric emptying studies. J. Nucl. Med. 24:264-268.

25. Bondar, R. J. L., and D. C. Mead. 1974. Evaluation of glucose6-phosphate dehydrogenase from leuconostoc mesenteroides in the hexokinase method for determining glucose in serum. Clin. Chem. 20:586-590.

26. Morgan, C. R., and A. L. Lazarow. 1963. Immunoassay of insulin: two antibody system. Diabetes. 12:115-126.

27. Solomon, T. E., T. Yamada, J. Elashoff, J. Wood, and C. Beglinger. 1984. Bioactivity of cholecystokinin analogs: CCK-8 is not more potent than CCK-33. Am. J. Physiol. 247:G105-G111.

28. Liddle, R. A., J. Elashoff, and J. R. Reeve, Jr. 1986. Relative bioactivities of cholecystokinins-8 and -33 on rat pancreatic acini. Peptides (NY). 7:723-727.

29. Winer, B. J. 1971. Statistical Principles in Experimental Design. McGraw-Hill Book Co., Inc., New York. 1-907.

30. Ivy, A. C., and E. Oldberg. 1928. A hormone mechanism for gallbladder contraction and evacuation. Am. J. Physiol. 65:599-613.

31. Harper, A. A., and H. S. Raper. 1943. Pancreozymin, a stimulant of secretion of pancreatic enzymes in extracts of the small intestine. J. Physiol. (Lond.). 102:115-125.

32. Levant, J., T. Kun, J. Jachna, R. Sturdevant, and J. Isenberg. 1974. The effects of graded doses of C-terminal octapeptide of cholecystokinin on small intestinal transit in man. Dig. Dis. 19:207-209.

33. Eysselein, V. E., J. R. Reeve, Jr., J. Shively, D. Hawke, and J. Walsh. 1982. Partial structure of a large canine cholecystokinin (CCK58): amino acid sequence. Peptides (NY). 3:687-691.

34. Mutt, V., and J. Jorpes. 1968. Structure of porcine cholecystokinin-pancreozymin. Eur. J. Biochem. 6:156-162.

35. Eng, J., B.-H. Du, Y.-C. Pan, M. Chang, J. Hulmes, and R. Yalow. 1984. Purification and sequencing of a rat intestinal 22 amino acid C-terminal CCK fragment. Peptides (NY). 5:1203-1206.

36. Rehfeld, J. F. 1978. Immunochemical studies on cholecystokinin. II. Distribution and molecular heterogeneity in the central nervous system and small intestine of man and hog. J. Biol. Chem. 253:4016-4021.

37. McIntyre, N., C. D. Holdsworth, and D. S. Turner. 1964. New interpretation of oral glucose tolerance. Lancet. ii:20-21.

38. Creutzfeldt, W., and R. Ebert. 1985. New developments in the incretin concept. Diabetologia. 38:565-573.

39. Dupre, J., S. A. Ross, D. Watson, and J. C. Brown. 1973. Stimulation of insulin secretion by gastric inhibitory polypeptide in man. Endocrinology. 37:826-828. 